\title{
Magnetic Properties of FePt Nanoparticles Prepared by Sonoelectrodeposition
}

\author{
Nguyen Hoang Nam, Nguyen Thi Thanh Van, Nguyen Dang Phu, Tran Thi Hong, \\ Nguyen Hoang Hai, and Nguyen Hoang Luong
}

VNU University of Science, 334 Nguyen Trai Road, Hanoi, Vietnam

Correspondence should be addressed to Nguyen Hoang Luong, luongnh@vnu.edu.vn

Received 24 March 2012; Accepted 26 April 2012

Academic Editor: Leonard Deepak Francis

Copyright (c) 2012 Nguyen Hoang Nam et al. This is an open access article distributed under the Creative Commons Attribution License, which permits unrestricted use, distribution, and reproduction in any medium, provided the original work is properly cited.

Sonoelectrodeposition is a useful technique to make metallic nanoparticles, using ultrasound during electrodeposition to remove nanoparticles as they grow on the cathode surface. This paper reports some structural and magnetic properties of FePt nanoparticles prepared by this method. The as-prepared $\mathrm{Fe}_{45} \mathrm{Pt}_{55}$ nanoparticles were ferromagnetic at room temperature. Upon annealing at $700^{\circ} \mathrm{C}$ for $1 \mathrm{~h}$ under $\mathrm{H}_{2}$ atmosphere, the saturation magnetization and the coercivity of the nanoparticles were improved significantly. The annealed nanoparticles showed a high coercivity of $13.5 \mathrm{kOe}$ at $2 \mathrm{~K}$ and of $9 \mathrm{kOe}$ at room temperature. Sonoelectrodeposition is a promising technique to make large quantity of FePt nanoparticles.

\section{Introduction}

The ordered face-centered tetragonal (fct) $\mathrm{L} 1_{0}$ FePt materials are normally obtained from the disordered face-centered cubic ( $\mathrm{fcc}$ ) materials via the order-disorder transition. The ordered FePt alloys possess excellent hard magnetic properties with the saturation magnetization, $\mu_{0} M_{s}$, of $1.4 \mathrm{~T}$, the Currie temperature, $T_{c}$, of $750 \mathrm{~K}$, and the crystalline anisotropy $K_{1}$, of $7 \mathrm{MJ} / \mathrm{m}^{3}$ [1]. Despite the high cost of Pt, FePt thin films or particles have been paid much attention to their use as ultrahigh density magnetic storage media and microelectronic mechanical system (MEMS) due to the mechanical and chemical stability of the ordered fct $\mathrm{L}_{0}$ structure.

There are several ways to make FePt-nanostructured materials including physical techniques such as mechanical deformation [2], arcmelting [3], vacuum evaporation (sputtering and thermal evaporation) $[4,5]$, laser ablation pulse [6], chemical methods [7-9], and physicochemical method such as electrodeposition $[10,11]$. Up to now, the vacuum evaporation is the most used method. Electrodeposition is a promising way to obtain FePt thin films because it is less expensive than physical methods, less complicated than chemical methods. But by this technique, it is difficult to get nanoparticles with large quantity. Sonoelectrochemistry was developed to make nanoparticles [12]. It combined the advantages of sonochemistry and electrodeposition. Sonochemistry is a very useful synthetic method which was discovered as early as 1934 that the application of ultrasonic energy could increase the rate of electrolytic water cleavage. The effects of ultrasonic radiation on chemical reactions are due to the very high temperatures and pressures, which develop in and around the collapsing bubble [13]. Sonoelectrochemistry has the potential benefit of combining sonochemistry with electrochemistry. Some of these beneficial effects include acceleration of mass transport, cleaning and degassing of the electrode surface, and an increased reaction rate [14]. In this paper, we report the use of the sonoelectrochemical method for the preparation of $\mathrm{FePt}$ nanoparticles. Recently, CoPt nanoparticles encapsulated in carbon cages prepared by sonoelectrodeposition have been reported by Luong et al. [15].

\section{Experimental}

The sonoelectrochemical device employed is similar to that described in [16]. A titanium horn with diameter of $1.3 \mathrm{~cm}$ acted as both the cathode and ultrasound emitter (Sonics 


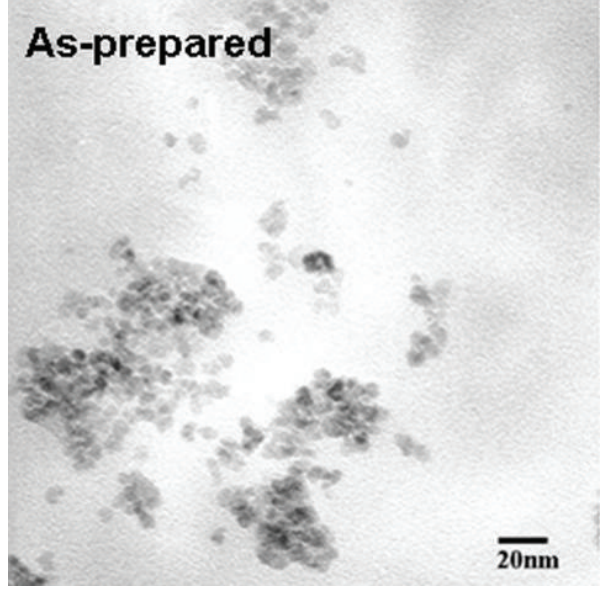

(a)

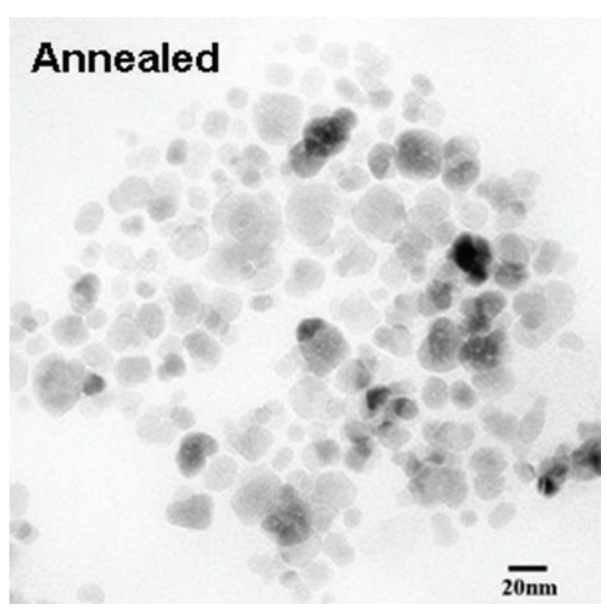

(b)

Figure 1: TEM images of the as-prepared (a) and annealed (b) $\mathrm{Fe}_{45} \mathrm{Pt}_{55}$ nanoparticles $\left(700^{\circ} \mathrm{C} / 1 \mathrm{~h}\right)$.

VCX 750). The electroactive part of the sonoelectrode was the planar circular surface at the bottom of the Ti horn. An isolating plastic jacket covered the immersed cylindrical part. This sonoelectrode produced a sonic pulse that immediately followed a current pulse. One pulse driver was used to control a galvanostat and the ultrasonic processor, which was adapted to work in the pulse mode. A home-made galvanostat (without using a reference electrode) was used to control the constant current regime. A platinum plate with a square of $1 \mathrm{~cm}^{2}$ was used as a counter electrode. The current pulse was $15 \mathrm{~mA} / \mathrm{cm}^{2}$. The ultrasound power density was $100 \mathrm{~W} / \mathrm{cm}^{2}$. The duration $t_{\text {on }}$ of the current pulse was $0.5-0.8 \mathrm{~s}$, then the current was turned off for a fixed duration $t_{\text {off }}$ of $0.5 \mathrm{~s}$. During $t_{\mathrm{on}}$, FePt nanoparticles were deposited on the surface of the electrode. When the current was switched off, an ultrasound was activated to remove the nanoparticles from the electrode. The time of ultrasound was $0.3 \mathrm{~s}$. The temperature during the reaction was room temperature. The volume of the electrolysis cell was $80 \mathrm{~mL}$ containing $1 \mathrm{mM} \mathrm{H}_{2} \mathrm{PtCl}_{6}, 0.1 \mathrm{M} \mathrm{FeSO}_{4}$, and $0.525 \mathrm{M} \mathrm{Na}_{2} \mathrm{SO}_{4}$. The chemicals were mixed under $\mathrm{N}_{2}$ atmosphere. The $\mathrm{pH}=3$ of the solution was controlled by $\mathrm{H}_{2} \mathrm{SO}_{4}$. After deposition, FePt nanoparticles were collected by using a centrifuge (Hettich Universal 320, $9000 \mathrm{rpm}$, $20 \mathrm{~min}$ ). Nanoparticles were dried in air at $80^{\circ} \mathrm{C}$ for $20 \mathrm{~min}$. All samples were annealed at $700^{\circ} \mathrm{C}$ for $1 \mathrm{~h}$ under $\mathrm{H}_{2}$ atmosphere. The structure of the nanoparticles was analyzed by using a Bruker D5005 X-ray diffractometer (XRD). The particle morphology was obtained from a transmission electron microscope (TEM JEM1010-JEOL). The chemical composition of the FePt nanoparticles was studied by using an energy dispersion spectroscopy (EDS OXFORD-ISIS 300) and revealed that the chemical composition of our sample is $\mathrm{Fe}_{45} \mathrm{Pt}_{55}$. Magnetic measurements were conducted by using Quantum Design's superconducting quantum interference device (SQUID) with a magnetic field up to $50 \mathrm{kOe}$ at temperature range from $2 \mathrm{~K}$ to $300 \mathrm{~K}$.

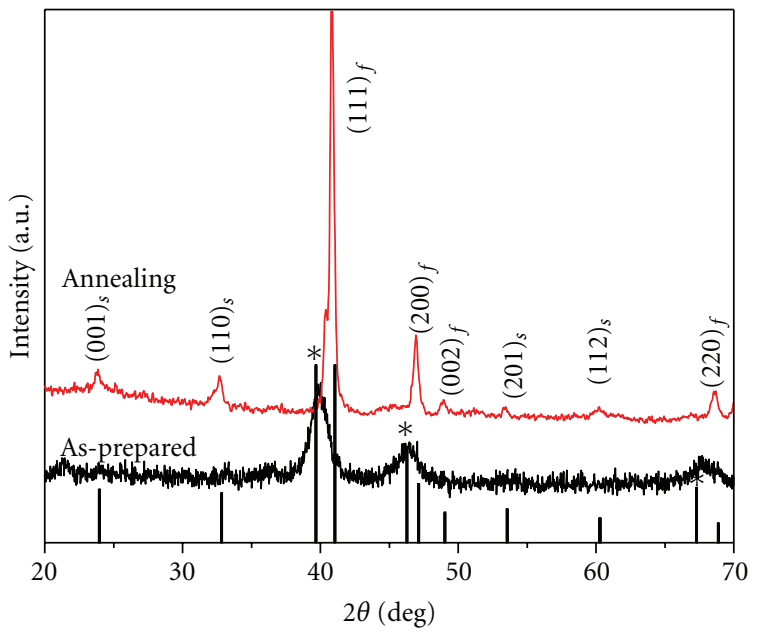

FIGURE 2: XRD patterns ( $\mathrm{Cu} \mathrm{K} \alpha$ radiation) of the as-prepared (bottom) and annealed (top) $\mathrm{Fe}_{45} \mathrm{Pt}_{55}$ nanoparticles compared to those of the intensities for $\mathrm{L}_{0}$ FePt (PDF file 431359) and for Pt (marked by the asterisks, PDF file 04-0802). The fundamental peaks of FePt structure were denoted by " $f$," and the superlattice peaks were denoted by "s."

\section{Results and Discussion}

Figure 1 is the TEM images of typical as-prepared and annealed samples. Particle size of the as-prepared $\mathrm{Fe}_{45} \mathrm{Pt}_{55}$ sample was $5-10 \mathrm{~nm}$. After annealing the particle size increased to $10-25 \mathrm{~nm}$ due to the aggregation and particle growth. In addition, the size distribution of the annealed particles was larger than that of the as-prepared samples.

Figure 2 shows the XRD patterns of the as-prepared and the annealed $\mathrm{Fe}_{45} \mathrm{Pt}_{55}$ nanoparticles $\left(700^{\circ} \mathrm{C}\right.$ for $\left.1 \mathrm{~h}\right)$. Before annealing, the XRD results showed the reflections of pure Pt structure, which is similar to other FePt thin films produced by electrodeposition [17]. However, authors in 
[17] thought that the reflections were from the disordered fcc phase. For the fcc phase, XRD results present only the fundamental reflections which are (111), (200), and (220). The fundamental reflections of the fcc FePt are close to the (111), (200), and (220) reflections of the Pt that make some scientists thought that they are of the fcc structure. We propose that XRD results from our as-prepared nanoparticles and from [17] are the peaks of only Pt. The reflections from $\mathrm{Fe}$ are very weak due to the fact that their atomic weight is much less than that of Pt which is similar to the XRD result of FePt foils prepared by cold deformation [18]. The Pt peaks in the as-prepared samples are broad due to the small size of the particles. Using the Scherrer formula with the full width at half maximum of the strongest peak (111), the mean particle size of Pt particles was deduced to be $5.2 \mathrm{~nm}$, which is much smaller than the particle size obtained from the TEM image. The particles were not disordered FePt, but they can be formed by many small domains of pure Fe and Pt. The formation of FePt by electrodeposition did not occurr and may be ascribed to the large difference in the standard electrode potential of the $\mathrm{Fe}^{2+} / \mathrm{Fe}(-0.44 \mathrm{~V}$ [19]) and $\mathrm{Pt}^{4+} / \mathrm{Pt}(0.742 \mathrm{~V}[20])$. Upon annealing, the formation of the ordered $\mathrm{L} 1_{0}$ fct phase happened by the diffusion process between Fe and Pt domains.

Magnetic measurements revealed low-saturation magnetization $\left(M_{s}\right)$ and coercivity $\left(H_{c}\right)$ in all as-prepared samples (data not shown). The saturation magnetization of the unannealed particles was about few emu/g and the coercivity was $20-80 \mathrm{kOe}$. The low value of $M_{s}$ of the asprepared nanoparticles may be explained by the oxidation or hydroxidation of $\mathrm{Fe}$ atoms in nanoparticles, which can result in the weak magnetic iron oxides and iron hydroxides. This is in agreement with the suggestion of separated $\mathrm{Fe}$ and $\mathrm{Pt}$ domains in as-prepared nanoparticles. It is known that FePt with high-saturation magnetization is a chemically stable material. Therefore, it is difficult to be oxidized to form weak ferromagnetic materials. After annealing, the hard magnetic FePt phase was formed. Figure 3 presents the magnetic curves of the annealed $\mathrm{Fe}_{45} \mathrm{Pt}_{55}$ at different temperatures. The curves show a typical hard magnetic hysteresis loops with high $H_{c}$. Beside, form of the magnetic curves shows that a small soft magnetic phase, probably $\mathrm{FePt}_{3}$, exists in the sample. The as-prepared $\mathrm{Fe}_{45} \mathrm{Pt}_{55}$ nanoparticles were ferromagnetic at room temperature. Upon annealing at $700^{\circ} \mathrm{C}$ for $1 \mathrm{~h}$, the saturation magnetization and the coercivity of the nanoparticles were improved significantly. Coercivity of annealed $\mathrm{Fe}_{45} \mathrm{Pt}_{55}$ nanoparticles as a function of temperature is shown in Figure 4. At $2 \mathrm{~K}$, the coercivity is $13.5 \mathrm{kOe}$ and slightly decreases with increasing temperature to the value of $9 \mathrm{kOe}$ at $300 \mathrm{~K}$.

Magnetic squareness $S=M_{r} / M_{s}$ of annealed $\mathrm{Fe}_{45} \mathrm{Pt}_{55}$ nanoparticles as a function of temperature is shown in Figure 5. The temperature dependence of $S$ is similar to that of $H_{c}$. At $2 \mathrm{~K}$, the magnetic squareness is 0.78 , slightly decreases with increasing temperature, and has a value of 0.745 at $300 \mathrm{~K}$. This value of $S$ is very close to that obtained for $\mathrm{L}_{0} \mathrm{CoPt}$ nanoparticles at room temperature [15].

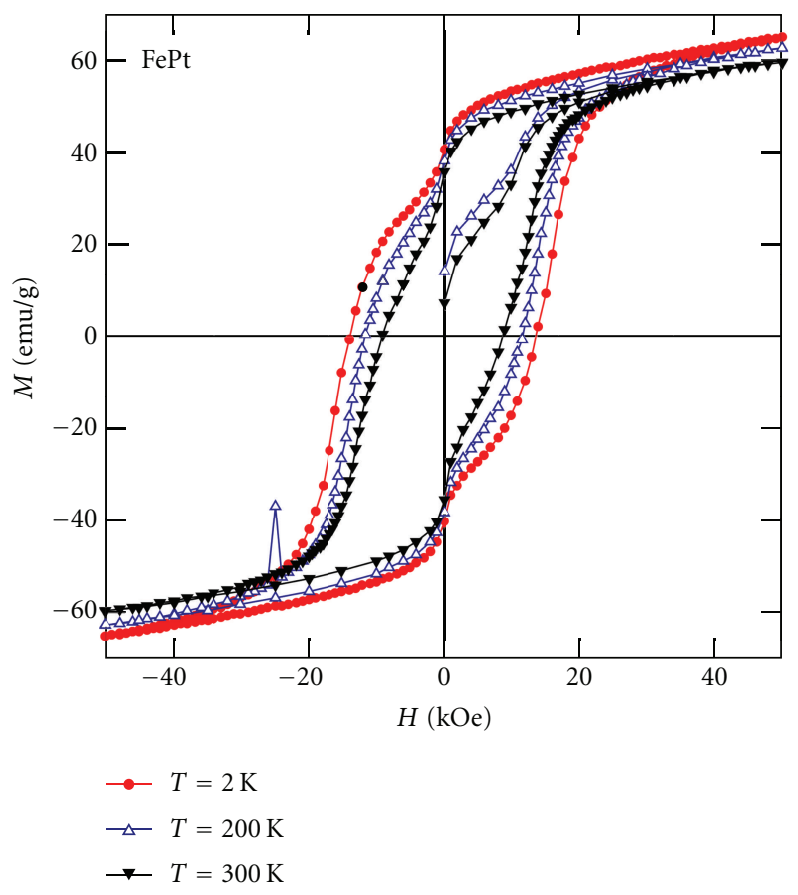

FIgURE 3: Magnetic curves of annealed $\mathrm{Fe}_{45} \mathrm{Pt}_{55}$ nanoparticles at different temperatures.

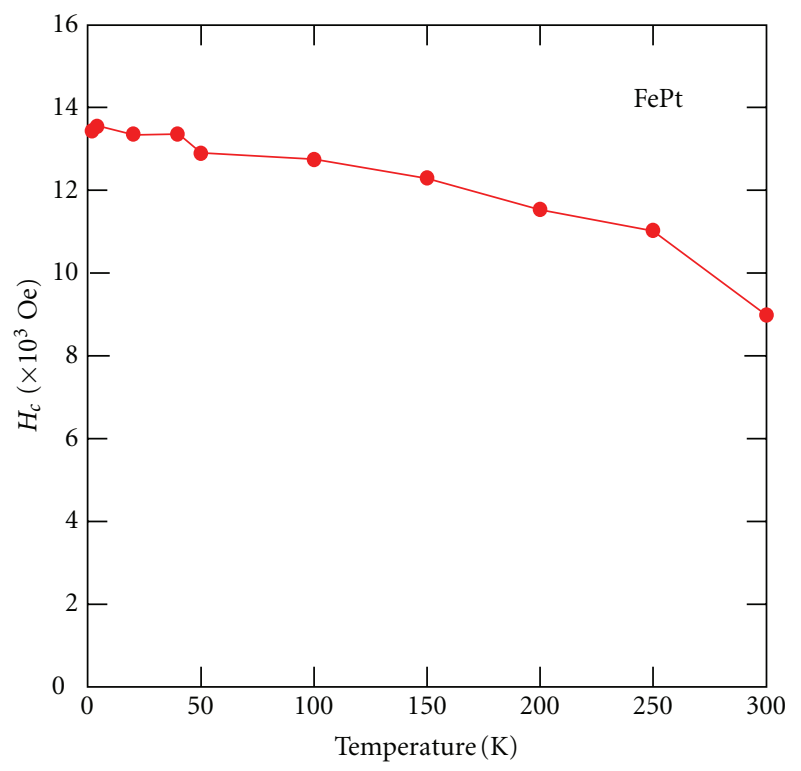

FIgURE 4: Coercivity of annealed $\mathrm{Fe}_{45} \mathrm{Pt}_{55}$ nanoparticles as a function of temperature.

\section{Conclusion}

Sonoelectrochemistry is a promising method to make FePt magnetic nanoparticles. The annealed FePt nanoparticles made by this technique had the size of $10-25 \mathrm{~nm}$. After annealing, the nanoparticles showed a high coercivity of $13.5 \mathrm{kOe}$ at $2 \mathrm{~K}$ and $9 \mathrm{kOe}$ at room temperature. This method possesses some advantages compared to common methods 


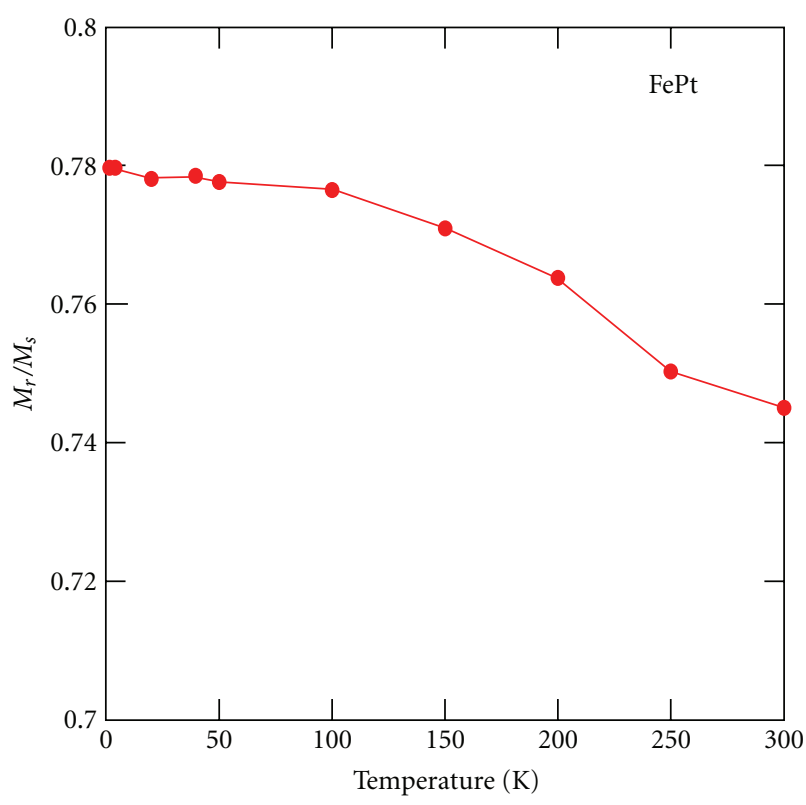

Figure 5: Magnetic squareness $S=M_{r} / M_{s}$ of annealed $\mathrm{Fe}_{45} \mathrm{Pt}_{55}$ nanoparticles as a function of temperature.

such as simple preparation, low-cost equipment, and easy scaleup.

\section{Acknowledgments}

The authors would like to thank the National Foundation for Science and Technology Development of VietnamNAFOSTED (project 103.02.72.09) for financial support. N. H. Nam is grateful to the TRIG A Project of Hanoi University of Science, Vietnam National University, Hanoi for support to complete the paper at Nottingham University, Nottingham, United Kingdom. The authors would like to thank Professor Y. Nozue of Osaka University, Japan, for providing SQUID.

\section{References}

[1] A. Cebollada, R. F. C. Farrow, and M. F. Toney, "Structure and magnetic properties of chemically ordered magnetic binary alloys in thin film form," in Magnetic Nanostructure, H. S. Nalwa, Ed., p. 93, American Scientific, Stevenson Ranch, Calif, USA, 2002.

[2] N. H. Hai, N. M. Dempsey, M. Veron, M. Verdier, and D. Givord, "An original route for the preparation of hard FePt," Journal of Magnetism and Magnetic Materials, vol. 257, no. 2-3, pp. L139-L145, 2003.

[3] Q. I. Xiao, P. D. Thang, E. Brück, F. R. De Boer, and K. H. J. Buschow, "Effect of phase transformation on remanence enhancement in bulk Fe-Pt magnets," Applied Physics Letters, vol. 78, no. 23, pp. 3672-3674, 2001.

[4] N. T. T. Van, N. H. Hai, N. H. Luong, V. V. Hiep, and N. Chau, "Magnetic properties of $(\mathrm{FePt})_{100-\mathrm{x}} \mathrm{Cu}_{\mathrm{x}}$ thin films," Journal of the Korean Physical Society, vol. 52, no. 5, pp. 1435-1438, 2008.

[5] N. H. Luong, V. V. Hiep, D. M. Hong et al., "High-coercivity FePt sputtered films," Journal of Magnetism and Magnetic Materials, vol. 290-291, pp. 559-561, 2005.
[6] L. J. Qiu, J. Ding, A. O. Adeyeye et al., "FePt patterned media fabricated by deep UV lithography followed by sputtering or PLD," IEEE Transactions on Magnetics, vol. 43, no. 6, pp. 21572159, 2007.

[7] S. Saita and S. Maenosono, "FePt nanoparticles with a narrow composition distribution synthesized via pyrolysis of iron(III) ethoxide and platinum(II) acetylacetonate," Chemistry of Materials, vol. 17, no. 14, pp. 3705-3710, 2005.

[8] R. Harpeness and A. Gedanken, "The microwave-assisted polyol synthesis of nanosized hard magnetic material, FePt," Journal of Materials Chemistry, vol. 15, pp. 698-702, 2005.

[9] S. Sun, C. B. Murray, D. Weller, L. Folks, and A. Moser, "Monodisperse FePt nanoparticles and ferromagnetic FePt nanocrystal superlattices," Science, vol. 287, no. 5460, pp. 1989-1992, 2000.

[10] K. Žužek Rožman, A. Krause, K. Leistner, S. Fähler, L. Schultz, and H. Schlörb, "Electrodeposition and hard magnetic properties of Co-Pt films in comparison to Fe-Pt films," Journal of Magnetism and Magnetic Materials, vol. 314, no. 2, pp. 116121, 2007.

[11] F. M. F. Rhen, G. Hinds, C. O'Reilly, and J. M. D. Coey, "Electrodeposited FePt films," IEEE Transactions on Magnetics, vol. 39, no. 5, pp. 2699-2701, 2003.

[12] A. Gedanken, "Novel methods (sonochemistry, microwave heating, and sonoelectrochemistry) for the preparation of nanosized iorganic compounds," in Inorganic Materials: Recent Advances, D. Bahadur, S. Vitta, and O. Prakash, Eds., p. 302, Narosa Pu blishing, Delhi, India, 2002.

[13] K. S. Suslick, S. B. Choe, A. A. Cichowlas, and M. W. Grinstaff, "Sonochemical synthesis of amorphous iron," Nature, vol. 353, no. 6343, pp. 414-416, 1991.

[14] T. J. Mason, J. P. Lorimer, and D. J. Walton, "Sonoelectrochemistry," Ultrasonics, vol. 28, no. 5, pp. 333-337, 1990.

[15] N. H. Luong, N. H. Hai, N. D. Phu, and D. A. MacLaren, "Co-Pt nanoparticles encapsulated in carbon cages prepared by sonoelectrodeposition," Nanotechnology, vol. 22, no. 28, Article ID 285603, 2011.

[16] J. Zhu, S. T. Aruna, Y. Koltypin, and A. Gedanken, "A novel method for the preparation of lead selenide: pulse sonoelectrochemical synthesis of lead selenide nanoparticles," Chemistry of Materials, vol. 12, no. 1, pp. 143-147, 2000.

[17] Q. Zeng, Y. Zhang, H. L. Wang, V. Papaefthymiou, and G. C. Hadjipanayis, "Magnetic properties and microstructure of fine Fe-Pt nanoparticles prepared by chemical reduction," Journal of Magnetism and Magnetic Materials, vol. 272-276, no. 1, pp. e1223-e1225, 2004.

[18] N. H. Hai, N. M. Dempsey, and D. Givord, "Hard magnetic FePt alloys prepared by cold-deformation," Journal of Magnetism and Magnetic Materials, vol. 262, no. 3, pp. 353-360, 2003.

[19] P. Atkins, Physical Chemistry, W.H. Freeman and Company, New York, NY, USA, 6th edition, 1997.

[20] A. J. Bard and L. R. Faulkner, Electrochemical Methods: Fundamentals and Applications, John Wiley and Sons, New York, NY, USA, 2nd edition, 2001. 

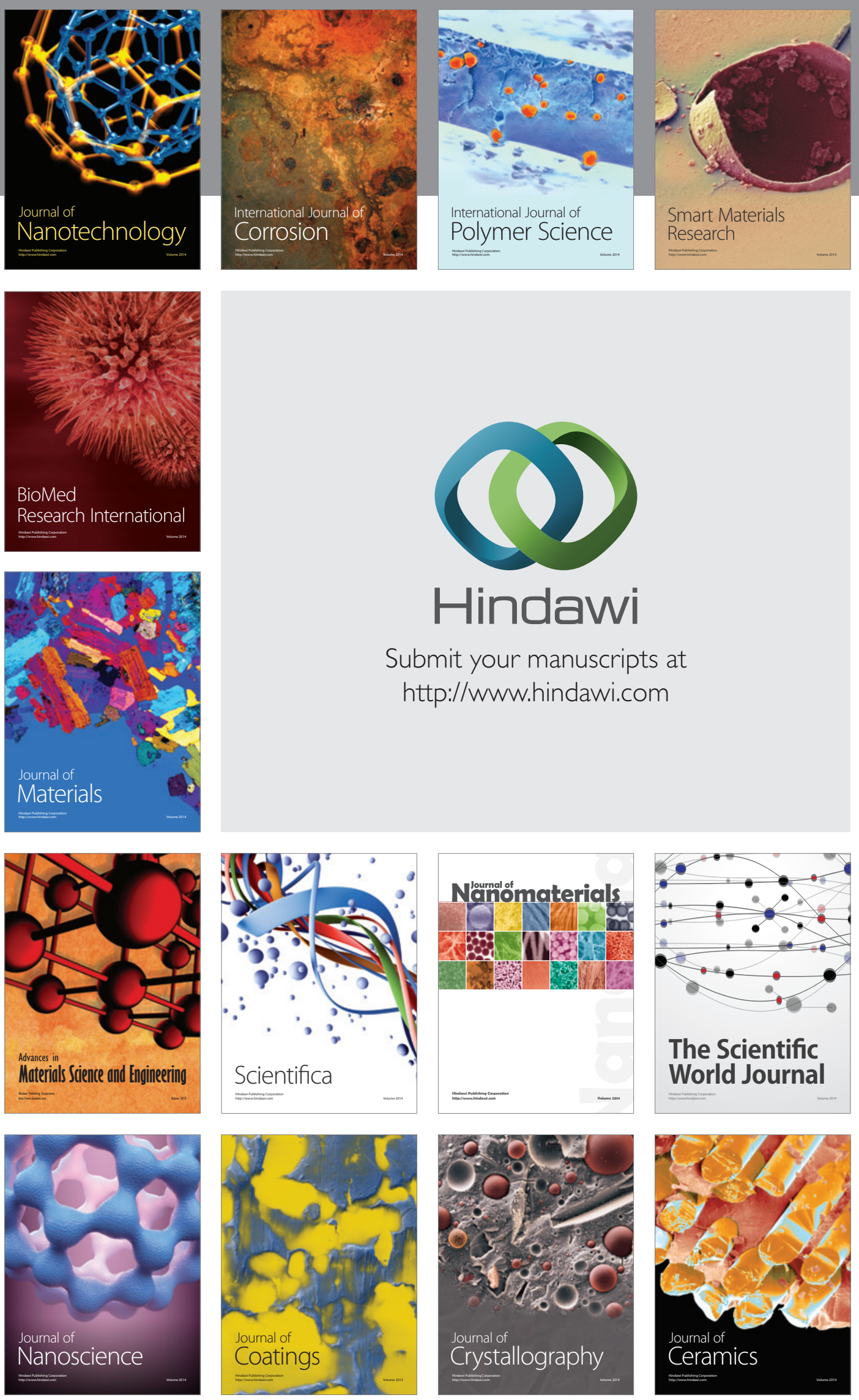

The Scientific World Journal

Submit your manuscripts at

http://www.hindawi.com

\section{World Journal}

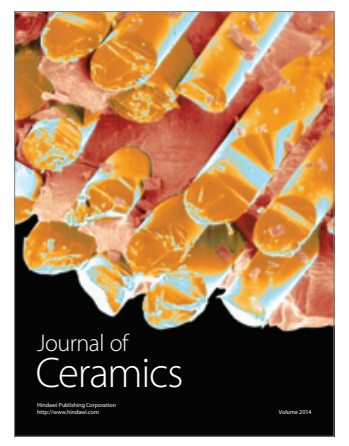

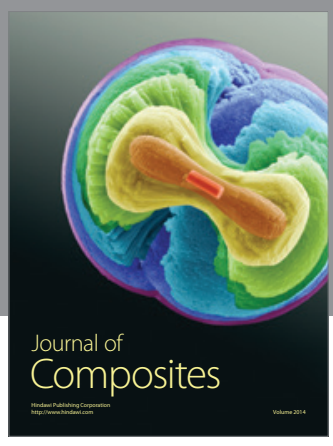
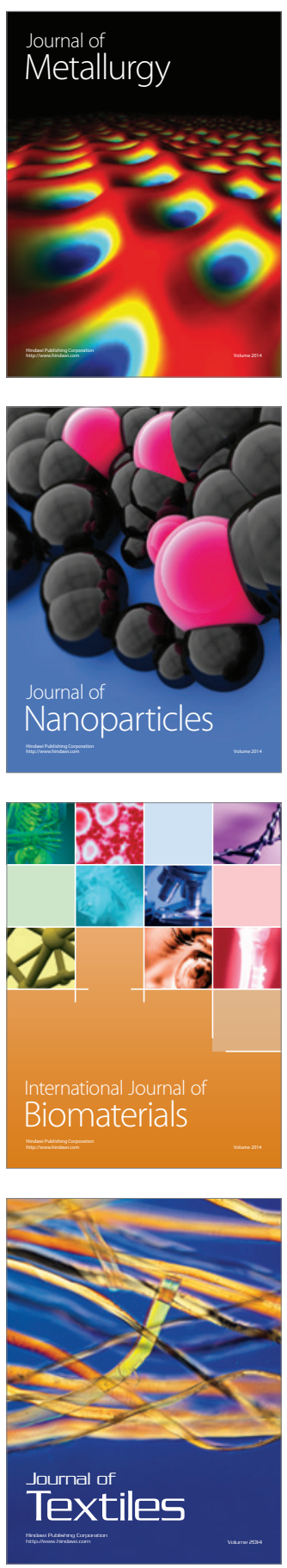